\title{
Correction to: Apathy and Depression as Predictors of Activities of Daily Living Following Stroke and Traumatic Brain Injuries in Adults: a Meta-Analysis
}

\author{
Sarah L. Green ${ }^{1} \cdot$ Gilles E. Gignac $^{1}$ (D) $\cdot$ Prue A. Watson $^{1} \cdot$ Nicky Brosnan $^{1} \cdot$ Rodrigo Becerra $^{1} \cdot$ Carmela Pestell $^{1}$. \\ Michael Weinborn ${ }^{1}$
}

Published online: 26 April 2021

๑) Springer Science+Business Media, LLC, part of Springer Nature 2021

\section{Correction to: Neuropsychology Review https://doi.org/10.1007/s11065-021-09501-8}

The author group in the original version of this article contained a mistake. The 6th author's name should be Carmela Pestell, instead of Carmella Pestell. The correct name appears above.

The original article has been corrected.
The original article can be found online at https://doi.org/10.1007/ s11065-021-09501-8.

\section{Gilles E. Gignac}

gilles.gignac@uwa.edu.au

1 School of Psychology, University of Western Australia, 35 Stirling Highway, Crawley, WA 6009, Australia
Publisher's Note Springer Nature remains neutral with regard to jurisdictional claims in published maps and institutional affiliations. 